Proc. Estonian Acad. Sci. Geol., 2004, 53, 1, 3-12

\title{
Surface exposure dating using in situ cosmogenic ${ }^{10} \mathrm{Be}$
}

\author{
Roland Zech ${ }^{\mathrm{a}}$, Uwe Abramowski ${ }^{\mathrm{a}}$, Bruno Glaser ${ }^{\mathrm{a}}$, \\ Peter W. Kubik ${ }^{\mathrm{b}}$, and Wolfgang Zech ${ }^{\mathrm{a}}$ \\ a Institute of Soil Science and Soil Geography, University of Bayreuth, D-95440 Bayreuth, \\ Germany; wolfgang.zech@uni-bayreuth.de \\ b Paul Scherrer Institute, c/o Institute of Particle Physics, HPK H30, ETH Hoenggerberg, CH-8093 \\ Zurich, Switzerland
}

Received 16 September 2003

\begin{abstract}
Surface exposure dating using in situ cosmogenic ${ }^{10} \mathrm{Be}$ in quartz is an important new tool in Quaternary research. We give an introduction into the method and describe, how ${ }^{10} \mathrm{Be}$ surface exposure ages are measured and calculated at the Institute of Soil Science and Soil Geography at the University of Bayreuth, Germany.
\end{abstract}

Key words: in situ cosmogenic ${ }^{10} \mathrm{Be}$, surface exposure dating.

\section{MOTIVATION}

Surface exposure dating using in situ cosmogenic ${ }^{10} \mathrm{Be}$ in quartz is an important new tool for Quaternary geologists in reconstructing glacial and nonglacial landscape development, especially where suitable organic material for radiocarbon dating is lacking. The method was developed in the 1990s and since then has been significantly improved. It is now used as a standard procedure of determining exposure ages of erratic boulders and the respective moraines (e.g. Gosse et al. 1995; Owen et al. 2002), glacially polished bedrock surfaces (e.g. Brook et al. 1996), terraces (e.g. Hancock et al. 1999), and landslides (Kubik et al. 1998). The method is straightforward and can be applied wherever suitable quartz-bearing rock surfaces are present. Here we give an introduction into the method and describe, how surface exposure ages are currently measured and calculated at the Institute of Soil Science and Soil Geography at the University of Bayreuth. 


\section{INTRODUCTION INTO ${ }^{10}$ Be SURFACE EXPOSURE DATING \\ Production of in situ cosmogenic ${ }^{10} \mathrm{Be}$}

In situ cosmogenic ${ }^{10} \mathrm{Be}$ in quartz is produced within the upper one to three metres of the Earth's surface by the interaction of the cosmic radiation with the $\mathrm{O}$ and $\mathrm{Si}$ atoms of the mineral. The rate of ${ }^{10} \mathrm{Be}$ production only depends on the amount of cosmic radiation reaching the sample and can be determined.

The cosmic radiation entering the Earth's atmosphere, the so-called primary radiation, is composed of galactic cosmic rays, protons with energies between 1 and $10^{10} \mathrm{GeV}$ (Lal \& Peters 1967), and of much lower energetic solar cosmic rays. The last ones reach the surface of the Earth only in negligible amounts, and are therefore not important for in situ production. Incoming primary cosmic protons first are modulated by the terrestrial magnetic field, which deflects all rays which have energies lower than a certain threshold, the so-called cutoff rigidity. The cutoff rigidity is dependent on the geomagnetic latitude. It is highest near the equator where the geomagnetic field lines run parallel to the surface, and lowest near the poles, where the geomagnetic field lines run normal to the surface (Gosse \& Phillips 2001). Firstly, the ${ }^{10}$ Be production at any site therefore depends on its geomagnetic position.

Having entered the atmosphere, the primary radiation in a cascade of nuclear reactions is transformed into secondary rays, mainly consisting of neutrons and muons (Gosse \& Phillips 2001). The secondary neutron flux is further attenuated on its way down to the Earth's surface due to successive collision with atmospheric nuclei. Secondly, the ${ }^{10} \mathrm{Be}$ production at any surface therefore depends on the amount of atmospheric nuclei encountered by the secondary radiation on its way there, and therefore on the altitude of the site and the structure of the atmosphere above it (Stone 2000). The pathlength of air, or any other matter, required to attenuate the radiation flux by the factor of $\exp (-1)$ is called the attenuation length $\Lambda$. For neutrons of the secondary cosmic radiation in the atmosphere, $\Lambda$ amounts to 130 $170 \mathrm{~g} \mathrm{~cm}^{-2}$ and depends on the energy spectrum of the radiation (Dunai 2000). Since near the equator only high-energy particles enter the atmosphere, $\Lambda$ is higher at low latitudes than at the poles. Beneath the solid surface, the attenuation length of secondary neutrons is about $150 \mathrm{~g} \mathrm{~cm}^{-2}$, which is equivalent to about $55 \mathrm{~cm}$ of rock.

In situ cosmogenic ${ }^{10} \mathrm{Be}$ in quartz is mainly produced by spallation with fast neutrons. Only in depth greater than $\sim 3 \mathrm{~m}$, production by muon interactions becomes important as well (Heisinger et al. 1997; Gosse \& Phillips 2001). There is no production by epithermal or thermal neutrons, as is the case with cosmogenic ${ }^{36} \mathrm{Cl}$ (Gosse \& Phillips 2001). The depth profile of ${ }^{10} \mathrm{Be}$ production in rocks is therefore approximately exponential.

The concentration of any cosmogenic nuclide, $N\left(\right.$ at $\left.^{-1}\right)$, in any rock surface increases with the exposure time $t$. For radioactive nuclides such as ${ }^{10} \mathrm{Be}$, this increase is countered by decay, and can in the simplest case be described by Eq. (1): 


$$
N=\frac{P}{\lambda}\left(1-e^{-\lambda t}\right),
$$

where $\lambda$ is the decay constant of ${ }^{10} \mathrm{Be}$. The calculation of the exposure time $t$ further requires only knowledge of the production rate $P$ and of the ${ }^{10} \mathrm{Be}$ concentration $N$.

\section{Production rates and scaling}

As explained above, the production rate of ${ }^{10} \mathrm{Be}$ in any rock depends on the intensity of the secondary cosmic ray flux reaching its surface, which in turn depends strictly on elevation and geomagnetic position, but mainly on latitude (Lal 1991). Scaling factors are used to calculate the production rates with regard to a reference location that has been chosen to be at sea level at high latitude (SLHL), where the production rate is independent of the geomagnetic field intensity. The production rate at this reference location can be determined by calibration studies, measuring the concentration of cosmogenic ${ }^{10} \mathrm{Be}$ in quartz of surfaces with independently known exposure ages.

Nishiizumi et al. (1989) first published a calibrated SLHL production rate of

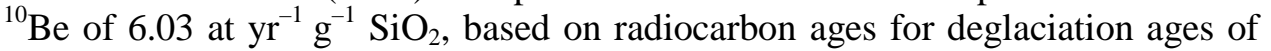
glacially polished rock surfaces in the Sierra Nevada and the scaling system of Lal (1991). Their independent dating was shown to be incorrect later, so they

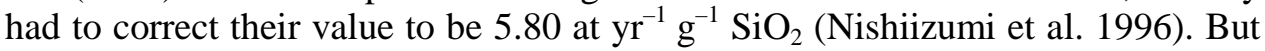
in another calibration study, using erratic boulder surfaces from a radiocarbon dated moraine, Clark et al. (1995) found a standard production rate of only 4.76 at $\mathrm{yr}^{-1} \mathrm{~g}^{-1} \mathrm{SiO}_{2}$. Other sudies followed, using exposed water targets (Nishiizumi et al. 1996), samples from Antarctic surfaces thought to be in equilibrium between production and decay (Ivy-Ochs 1996), as well as boulder surfaces from a radiocarbon dated landslide in Austria (Kubik et al. 1998), all yielding values in between these brackets. Stone (2000) improved the scaling system, reevaluated all published data and concluded that the best-fit production rate would be $5.1 \pm 0.3$ at $\mathrm{yr}^{-1} \mathrm{~g}^{-1} \mathrm{SiO}_{2}$ with a muon contribution of $2.6 \%$, which is much lower than previously accepted.

Meanwhile, other scaling systems have been published (Dunai 2001; Desilets $\&$ Zreda 2003), which try to achieve better fits to the empirical cosmic ray flux data and provide a better way of correcting for variations in the geomagnetic field, which adds a time dependency to the local production rates. When scaling with these systems, slightly different standard SLHL ${ }^{10} \mathrm{Be}$ production rates are obtained (e.g. Klein \& Gosse 2002; Schaller et al. 2002).

\section{Corrections}

Equation (1) is only a simplified approach to the real production equation (Gosse \& Phillips 2001). Several correction factors, to be multiplied with $P$ in Eq. (1), are necessary to get the actual local production rate for any surface. 


\section{Correction for sample thickness and cover}

Since production depends on the depth below the rock surface, the production rate must be averaged over the whole thickness of the rock sampled. The respective correction factor, $f_{\mathrm{ST}}$, can be calculated by integrating over the exponential depth profile of ${ }^{10} \mathrm{Be}$ production (Ivy-Ochs 1996):

$$
f_{\mathrm{ST}}=\frac{\Lambda}{\rho x}\left(1-\exp \left(-\frac{\rho x}{\Lambda}\right)\right) .
$$

Here, $x$ is the sample thickness in centimetres. The rock density $\rho$ can be estimated (e.g. $2.7 \mathrm{~g} \mathrm{~cm}^{-3}$ for granite). Masarik \& Reedy (1995) have shown that the first $12 \mathrm{~g} \mathrm{~cm}^{-2}$ of matter show no exponential decline in the production rate due to the effect of neutron backscattering. Therefore, Eq. (2) should be applied only for samples of more than $12 \mathrm{~g} \mathrm{~cm}^{-2}$ (calculated by taking $x$ times $\rho$ ) in thickness, using a weighted average of $P$ for $12 \mathrm{~g} \mathrm{~cm}^{-2}$ and $f_{\mathrm{ST}} P$ for $x \rho-12 \mathrm{~g} \mathrm{~cm}^{-2}$. Coverage of the samples with snow or soil as well as shielding by vegetation, if not negligible, must be taken into account in the calculation of the actual production rate. Its mass equivalent can be added on top of the sample thickness. Since snow and vegetation coverage are changing with climate, this correction can only be based on estimates in most cases. It should be considered if today's snow cover is heavy and lasts for three months or more, and/or if potential vegetation of the site consisted of a high, dense forest for more than half of the exposure period.

\section{Correction for topographic shielding}

Samples are often collected in the vicinity of topographic obstructions that shield the sample from parts of the cosmic ray flux. An inclination of the sampled surface also has an influence on the local production rate. Shielding factors for topographic shielding, using the dip angle of the horizon over each homogeneous interval of the azimuth, and for surface inclination, have been derived by Dunne et al. (1999). For high boulders, they can be applied separately. For low surfaces being actually part of the larger topography, like flat, glacially polished bedrock, an integrated factor concerning both shielding of the horizon and inclination has to be calculated.

\section{Correction for surface erosion}

Erosion of the rock surface causes a loss of accumulated in situ cosmogenic ${ }^{10} \mathrm{Be}$. Less enriched minerals are exposed so that the actual exposure age will be underestimated if no correction is applied. Continuous erosion can be corrected for by replacing the disintegration constant $\lambda$ with an effective disintegration constant, resulting from the erosion rate $\varepsilon\left(\mathrm{cm} \mathrm{yr}^{-1}\right)$, as shown in Eq. (3):

$$
\lambda^{*}=\lambda+\frac{\varepsilon \rho}{\Lambda} .
$$


The erosion rate should be determined independently, otherwise it must be estimated, adding a large error to the calculations. Unfortunately, methods for determining erosion rates of rock surfaces are not always accessible (the best available being the measurement of in situ cosmogenic ${ }^{36} \mathrm{Cl}$ or ${ }^{14} \mathrm{C}$ along with ${ }^{10} \mathrm{Be}$ ). Most of the previously published results therefore rely on estimates, even if the authors do not always consider the errors these estimates imply.

\section{Correction for tectonic uplift}

As the production rate depends on altitude, tectonic activity should be taken into account if samples are taken in tectonically active mountain ranges. In this case, exposure ages have to be calculated iteratively. If an uplift rate is known or can be estimated, a palaeoaltitude can be calculated for a number of time intervals leading back to the beginning of the exposure period of the sample, and an integrated production rate for all this time can be averaged from the production rates for the individual time steps.

Correction for changes in geomagnetic field intensity and position of the dipole axis

For surface exposure dating, the geomagnetic field is generally approximated by a geocentrical axial dipole (GAD hypothesis). At latitudes $<50^{\circ}$, the cosmic ray flux is strongly reduced by deflection, which is a function of the varying dipole moment. In addition, for exposure periods $<10 \mathrm{ka}$, the GAD hypothesis is not valid, so that changes of geomagnetic latitudes due to true polar wander have to be considered as well. As these geomagnetic effects are time dependent, they must be corrected for iteratively. The Sint200 record of Guyodo \& Valet (1996) and geomagnetic data of McElhinny \& Senanayake (1982), as well as the palaeopole position determined by Ohno \& Hamano (1992), can be used to calculate palaeogeomagnetic latitudes and dipole moments for time intervals of 0.5 to $1 \mathrm{ka}$ from the present to exposure periods of up to $200 \mathrm{ka}$. For each interval, an effective local production rate can be calculated. These can be averaged to give a corrected production rate for the whole exposure period. The iterative corrections for geomagnetic field variations and tectonic uplift can be implemented in parallel, after all previously mentioned corrections have already been applied.

\section{SAMPLING AND LABORATORY PROCEDURE}

Several (at least 3) selected, large quartz-containing surfaces should be sampled for each geomorphological feature. About $0.5-1 \mathrm{~kg}$ of rock, depending on the quartz content, altitude, and supposed age of the surface, should be chipped off or drilled from the upper few centimetres of the flat top of the surface, staying away from sharp edges and obviously spalled parts. Boulders with clear signs of erosion 
should be avoided, as well as boulders from the positions where post-depositional movement (e.g. solifluction) is possible. Altitude, geographic position, surface inclination, topographic shielding, height of the surface over ground, possible snow or vegetation cover as well as sample thickness must be documented at the site.

At our institute, we analyse samples following the slightly modified scheme of Ivy-Ochs (1996). In short, quartz is purified by selective chemical dissolution (Kohl \& Nishiizumi 1992) of the 0.5-2 mm fraction of the crushed and sieved rock. Samples are treated several times with 5\% HF to dissolve the feldspars and to etch away the meteoric ${ }^{10} \mathrm{Be}$ from the quartz surfaces. Heavy minerals and muscovite are removed by density fractionation. The remaining pure quartz is dissolved in $48 \% \mathrm{HF}$ after adding $450 \mu \mathrm{l}$ of $1000 \mathrm{ppm}{ }^{9} \mathrm{Be}$ carrier. Anion exchange chromatography (50 ml Biorad AG1-X8 100-200 mesh) and cation exchange chromatography ( $50 \mathrm{ml}$ Biorad AG $50 \mathrm{~W} \mathrm{X} 8, \mathrm{H}^{+}$form) are subsequently used to separate the Be. Be hydroxide is precipitated from the separate and transformed into $\mathrm{BeO}$ for AMS measurement. This is done at the ETH/PSI tandem facility in Zurich.

\section{CALCULATION OF THE EXPOSURE AGES}

From the measured ${ }^{10} \mathrm{Be} /{ }^{9} \mathrm{Be}$ ratios, blank corrected ${ }^{10} \mathrm{Be}$ concentrations $N$ in quartz are calculated using the weight of quartz dissolved and the amounts of carrier added. These, with their fully propagated errors, are used for the age calculation schemes. Since no consent has been reached as yet concerning the correct use of scaling and correction factors, three different schemes of calculations are employed.

\section{General procedure}

For iterative calculation of exposure ages we adopt the proposed scheme of Desilets \& Zreda (2003). We calculate the nuclide concentration $N$ resulting from $0.5,1,1.5$, etc. ka of exposure, changing to steps of $1 \mathrm{ka}$ after $10 \mathrm{ka}$, following Eq. (4),

$$
N(t)=\sum_{i=1}^{n} \frac{P_{0} S_{i} f_{\mathrm{ST}} f_{\mathrm{SCT}}}{\left(\lambda+\frac{\varepsilon \rho}{\Lambda}\right)}\left[1-\exp \left(-\Delta t_{i}\left(\lambda+\frac{\varepsilon \rho}{\Lambda}\right)\right)\right] \exp \left(-\sum_{i=1}^{n} \Delta t_{i}\left(\lambda+\frac{\varepsilon \rho}{\Lambda}\right)\right),
$$

where $P_{0}$ is the SLHL ${ }^{10} \mathrm{Be}$ standard production rate, $f_{\mathrm{ST}}$ and $f_{\mathrm{SCT}}$ are the correction factors for surface topography and surface cover and thickness, respectively, and $S_{i}$ is the scaling factor for the time interval $\Delta t_{i}$ resulting from the scaling system in question and the given values for geomagnetic latitude, atmospheric depth, and the geomagnetic virtual axial dipole moment (VADM). 
For $0.5-10 \mathrm{ka}$, we calculate geomagnetic latitude from geographic latitude and the palaeopole positions of Ohno \& Hamano (1992) by subtracting the palaeocolatitude from $90^{\circ}$ (Eq. (3.65) in Gosse \& Phillips 2001), from 11 ka onwards we use the GAD hypothesis and equate geographic and geomagnetic latitudes. Atmospheric depths are calculated using the physical standard atmosphere as cited in Stone (2000), which is within $0.2 \%$ of the ICAO atmosphere as cited by Dunai (2000). To correct for changing dipole intensity, we use the Sint-200 record of Guyodo \& Valet (1996), which is converted into absolute intensities by multiplying with $5.29 \times 10^{-22} \mathrm{Am}^{2}$ (Gosse \& Phillips 2001, fig. 7). We use a decay constant for ${ }^{10} \mathrm{Be}$ of $\lambda=4.56 \times 10^{-7} \mathrm{a}^{-1}$ (Holden 1990), a rock density of $\rho=2.7 \pm 0.5 \mathrm{~g} \mathrm{~cm}^{-3}$, and an attenuation length for spallation reactions in rock of $\Lambda=155 \pm 5 \mathrm{~g} \mathrm{~cm}^{-2}$ (Gosse \& Phillips 2001). The correction factor for topographic shielding $f_{\mathrm{ST}}$ is calculated according to Dunne et al. (1999), accounting for the surrounding relief and surface slope independently. The topographic shielding and surface slope correction for $\Lambda$ (Dunne et al. 1999) is also calculated and applied. The correction for surface cover and sample thickness is done in the following way. First, mean annual snow cover, if to be estimated realistically, and vegetation cover equivalent, if any, are subtracted from $12 \mathrm{~g} \mathrm{~cm}^{-2}$. The resulting equivalent is subtracted from the sample thickness. If there is a residual sample thickness equivalent left after subtraction, $f_{\mathrm{SCT}}$ is calculated for this thickness according to Eq. (2).

For the calculation of exposure ages, application of Eq. (4) is continued into the past until the measured nuclide concentration is reached. The exact age can be found by linear interpolation between the two age intervals bracketing the measured concentration.

\section{Calculation according to Stone (2000)}

Scaling factors according to Stone (2000) for each time interval are calculated using VADM corrected geomagnetic latitudes and atmospheric depths. VADM corrected latitudes $L_{\mathrm{c}}$ are calculated according to Eq. (5):

$$
\cos \left(L_{\mathrm{c}}\right)=\left(\frac{M}{M_{0}}\right)^{1 / 4} \cos \left(L_{\mathrm{gm}}\right),
$$

where $M$ is the averaged VADM for the time interval, and $M_{0}$ is today's VADM of $8.084 \times 10^{-22} \mathrm{Am}^{2}$ (Gosse \& Phillips 2001). The scaling parameters are interpolated between the 10 degree steps by fitting polynoms of the 5 th or 6 th grades between 20 and 50 degrees, and linear interpolation between all other latitudes. A standard production rate of $5.41 \pm 0.35$ with a muon contribution of $3.7 \%$ is used, which results from a rescaling of the calibration results from Kubik et al. (1998), including some additional, unpublished measurements, and using the SLHL muon production rates of Heisinger et al. (2002a, 2002b). 


\section{Calculation according to Dunai (2001)}

For scaling according to Dunai (2001), the inclination is calculated from geomagnetic latitude by the GAD formula $\tan (I)=2 \tan \left(L_{\mathrm{gm}}\right)$; the horizontal field strength $H$ and the palaeocolatitude $\theta$ are calculated according to Dunai's (2001) formulas (6) and (7), respectively. The cutoff rigidity is then calculated by Dunai's (2001) formula (2).

A standard production rate of $5.51 \pm 0.36$ with a muon contribution of $3.6 \%$ is used, which results from a rescaling of the calibration results from Kubik et al. (1998), including some additional, unpublished measurements, and using the SLHL muon production rates of Heisinger et al. (2002a, 2002b).

\section{Calculation according to Desilets \& Zreda (2003)}

For scaling according to Desilets \& Zreda (2003), atmospheric depth, geomagnetic latitude, and VADM in the form $M / M_{0}$ were used as required in their formulas. A standard production rate from neutrons of 5.24 \pm 0.35 is used, which derives from a rescaling of the calibration results of Kubik et al. (1998), including some additional, unpublished measurements, as well as the SLHL muon production rates of Heisinger et al. (2002a, 2002b).

\section{CONCLUDING REMARKS}

Surface exposure dating using in situ cosmogenic ${ }^{10} \mathrm{Be}$ has been carried out at the Institute of Soil Science and Soil Geography at the University of Bayreuth in the course of two years, relying on the cooperation with the AMS facility at ETH/PSI in Zurich. The method is straightforward and with current improvements will be applicable to a wide range of present and future topics in Quaternary geology. A set of ${ }^{10} \mathrm{Be}$ exposure ages from glacial moraines in Central Asia and Nepal has been measured and calculated as described above. Some results have already been published (Zech et al. 2003).

\section{REFERENCES}

Brook, E. J., Nesje, A., Lehman, S. J., Raisbeck, G. M. \& Yiou, F. 1996. Cosmogenic nuclide exposure ages along a vertical transect in western Norway: implications for the height of the Fennoscandian ice sheet. Geology, 24, 207-210.

Clark, D. H., Bierman, P. R. \& Larsen, P. 1995. Improving in situ cosmogenic chronometers. Quat. Res., 44, 366-376.

Desilets, D. \& Zreda, M. 2003. Spatial and temporal distribution of secondary cosmic-ray nucleon intensities and applications to in situ cosmogenic dating. Earth Planet. Sci. Let., 206, 21-42. 
Dunai, T. J. 2000. Scaling factors for production rates of in situ produced cosmogenic nuclides: a critical reevaluation. Earth Planet. Sci. Let., 176, 157-169.

Dunai, T. J. 2001. Influence of secular variation of the geomagnetic field on production rates of in situ produced cosmogenic nuclides. Earth Planet. Sci. Let., 193, 197-212.

Dunne, D., Elmore, D. \& Muzikar, P. 1999. Scaling factors for the rates of production of cosmogenic nuclides for geometric shielding and attenuation at depth on sloped surfaces. Geomorphology, 27, 3-11.

Gosse, J. C. \& Phillips, F. M. 2001. Terrestrial in situ cosmogenic nuclides: theory and application. Quat. Sci. Rev., 20, 1475-1560.

Gosse, J. C., Klein, J., Evenson, E. B., Lawn, B. \& Middleton, R. 1995. Beryllium-10 dating of the duration and retreat of the last Pinedale Glacial Sequence. Science, 268, 1329-1333.

Guyodo, Y. \& Valet, J. P. 1996. Relative variation in geomagnetic intensity from sedimentary records: the past 200,000 years. Earth Planet. Sci. Let., 143, 23-36.

Hancock, G. S., Anderson, R. S., Chadwick, O. A. \& Finkel, R. C. 1999. Dating fluvial terraces with ${ }^{10} \mathrm{Be}$ and ${ }^{26} \mathrm{Al}$ profiles: application to the Wind River, Wyoming. Geomorphology, 27, 41-60.

Heisinger, B., Niedermayer, M., Hartmann, J. F., Korschinek, G., Nolte, E., Morteani, G., Neumaier, S., Petitjean, C., Kubik, P., Synal, A. \& Ivy-Ochs, S. 1997. In-situ production of radionuclides at great depth. Nucl. Instrum. Meth. Phys. Res. B, 123, 341-346.

Heisinger, B., Lal, D., Jull, A. J. T., Kubik, P., Ivy-Ochs, S., Knie, K. \& Nolte, E. 2002a. Production of selected cosmogenic radionuclides by muons 2. Capture of negative muons. Earth Planet. Sci. Let., 200, 357-369.

Heisinger, B., Lal, D., Jull, A. J. T., Kubik, P., Ivy-Ochs, S., Neumaier, S., Knie, K., Lazarev, V. \& Nolte, E. 2002b. Production of selected cosmogenic radionuclides by muons 1. Fast muons. Earth Planet. Sci. Let., 200, 345-355.

Holden, N. E. 1990. Total half-lives for selected nuclides. Pure and Appl. Chem., 62, 941-958.

Ivy-Ochs, S. 1996. The dating of rock surface using in situ produced ${ }^{10} \mathrm{Be},{ }^{26} \mathrm{Al}$ and ${ }^{36} \mathrm{Cl}$, with examples from Antarctica and the Swiss Alps. Diss. ETH No. 11763, Zürich.

Klein, J. \& Gosse, J. C. 2002. Production rates of ${ }^{10} \mathrm{Be}$ and ${ }^{26} \mathrm{Al}$ in mid-latitudes and high altitudes. Geochim. Cosmochim. Acta, 6b, Suppl. 1, A 403 (Goldschmidt Conference Abstracts 2002).

Kohl, C. P. \& Nishiizumi, K. 1992. Chemical isolation of quartz for measurement of in situ produced cosmogenic nuclides. Geochim. Cosmochim. Acta, 56, 3583-3587.

Kubik, P. W., Ivy-Ochs, S., Masarik, J., Frank, M. \& Schlüchter, C. $1998 .{ }^{10}$ Be and ${ }^{26} \mathrm{Al}$ production rates deduced from an instantaneous event within the dendro-calibration curve, the landslide of Köfels, Ötz Valley, Austria. Earth Planet. Sci. Let., 161, 231-241.

Lal, D. 1991. Cosmic ray labelling of erosion surfaces: in situ nuclide production rates and erosion models. Earth Planet. Sci. Let., 104, 424-439.

Lal, D. \& Peters, B. 1967. Cosmic ray produced radioactivity on the Earth. In Handbuch der Physik, Vol. 46/2 (Flugge, S., ed.), pp. 551-612. Springer-Verlag, Berlin.

Masarik, J. \& Reedy, R. C. 1995. Terrestrial cosmogenic-nuclide production systematics calculated from numerical simulations. Earth Planet. Sci. Let., 136, 381-395.

McElhinny, M. W. \& Senanayake, W. E. 1982. Variations in the geomagnetic dipole 1: the past 50,000 years. J. Geomagn. Geoelectr., 34, 39-51

Nishiizumi, K., Winterer, E. L., Kohl, C. P., Klein, J., Middelton, R., Lal, D. \& Arnold, J. R. 1989. Cosmic ray production rates of ${ }^{10} \mathrm{Be}$ and ${ }^{26} \mathrm{Al}$ in quartz from glacially polished rocks. J. Geophys. Res., 94, 17907-17915.

Nishiizumi, K., Finkel, R. C., Klein, J. \& Kohl, C. P. 1996. Cosmogenic production of ${ }^{7} \mathrm{Be}$ and ${ }^{10} \mathrm{Be}$ in water targets. J. Geophys. Res., 101, 22225-22232.

Ohno, M. \& Hamano, Y. 1992. Geomagnetic poles over the past 10,000 years. Geophys. Res. Let., 19, 1715-1718.

Owen, L. A., Finkel, R. C., Caffee, M. W. \& Gualtieri, L. 2002. Timing of multiple glaciations during the Late Quaternary in the Hunza Valley, Karakoram Mountains, northern Pakistan: defined by cosmogenic radionuclide dating of moraines. GSA Bulletin, 114, 593-604. 
Schaller, M., Von Blanckenburg, F., Veldkamp, A., Tebbens, L. A., Hovius, N. \& Kubik, P. W. 2002. A $30000 \mathrm{yr}$ record of erosion rates from cosmogenic ${ }^{10} \mathrm{Be}$ in Middle European river terraces. Earth Planet. Sci. Let., 204, 307-320.

Stone, J. O. 2000. Air pressure and cosmogenic isotope production. J. Geophys. Res., 105, 2375323759.

Zech, W., Abramowski, U., Zech, R. \& Glaser, B. 2003. Experiences with ${ }^{10}$ Be surface exposure dating of boulders from Central Asian moraines. In International Symposium on Human Impact and Geological Heritage, 12-17 May 2003, Tallinn, Estonia: Excursion Guide and Abstracts (Raukas, A. \& Kukk, H., eds.), pp. 139-140. Institute of Geology at Tallinn Technical University, Tallinn.

\title{
In situ kosmogeense ${ }^{10} \mathrm{Be}$ kasutamine dateerimisel
}

\author{
Roland Zech, Uwe Abramowski, Bruno Glaser, \\ Peter W. Kubik ja Wolfgang Zech
}

Antakse ülevaade berülliumimeetodi $\left({ }^{10} \mathrm{Be}\right)$ kasutamisest Kvaternaari setete dateerimisel ja tutvustatakse Saksamaal Bayreuthi Ülikooli Mullateaduse ja Mullageograafia Instituudis kasutatavat metoodikat. 